\title{
Types and prevalence of HIV-related opportunistic infections/conditions among HIV-positive patients attending Kenyatta National Hospital in Nairobi, Kenya
}

\author{
Geoffrey K Chepkondol ${ }^{1}$, Pauline E Jolly ${ }^{1}$, Nelly Yatich ${ }^{1}$, Omar Mbowe ${ }^{2}$, Walter G Jaoko ${ }^{3}$
}

1. Department of Epidemiology, University of Alabama at Birmingham School of Public Health, 1665 University Blvd Birmingham, Alabama, United States.

2. Department of Biostatistics, University of Alabama at Birmingham School of Public Health, 1665 University Blvd Birmingham, Alabama, United States.

3. Department of Medical Microbiology, University of Nairobi, P.O BOX 19676-00202, Nairobi, Kenya, Kenya AIDS Vaccine Initiative (KAVI), School of Medicine, University of Nairobi, P.O. BOX 19667600202, Nairobi, Kenya.

\section{Emails}

Geoffrey KChepkondol, kchepkondol@yahoo.com; Nelly Yatich, yatich@gmail.com; Omar Mbowe, omarmbowe@yahoo.com; Walter G Jaoko,wjaoko@kaviuon.org

\begin{abstract}
Background: Although antiretroviral therapy (ART) has resulted in significant decrease in opportunistic infections (OIs), OIs continue to cause significant morbidity and mortality among HIV patients.

Objective: To determine the prevalence and types of HIV/AIDS-related OIs among patients attending Kenyatta National Hospital (KNH) in Nairobi, Kenya.

Methods: A cross-sectional study was conducted from May to August 2010 among patients $\geq 19$ years. An interviewer-administered questionnaire was used to collect data on socio-demographic factors, HIV and OIs. CD4 data were extracted from clinical records.

Results: Most patients (72\%) had lived with HIV for $\leq 5$ years and $78.8 \%$ had an OI. The 3 most common OIs were TB (35\%), Herpes Zoster (HZ; 15.4\%) and oral thrush (OT; 8\%). Years of HIV infection significantly predicted TB ( $\mathrm{p}=0.01)$. Patients with CD $4 \leq 349$ were almost twice as likely to have TB, than those with CD4 $\geq 500$. Type of occupation predicted OT $(p=0.04)$ with skilled workers less likely to have OT. Patients with primary/vocational/technical education were $>3$ times more likely to have HZ than those with tertiary education.

Conclusion: Due to the complex management of HIV and its associated OIs, appropriate implementation of the recommended guidelines for care and prevention among patients at $\mathrm{KNH}$ is important.

Keywords: HIV-related opportunistic infections, Kenyatta National Hospital, Kenya.

DOI: https://doi.org/10.4314/ahs.v20i2.9

Cite as: Chepkondol GK, Jolly PE, Yatich N, Mbowe O, Jaoko WG. Types and prevalence of HIV-related opportunistic infections/conditions among HIV-positive patients attending Kenyatta National Hospital in Nairobi, Kenya. Afri Health Sci. 2020; 20(2): 615-624. https:// doi. org/10.4314/ahs.v20i2.9
\end{abstract}

\section{Introduction}

Human Immunodeficiency Virus (HIV) and Tubercu-

Corresponding author:
Pauline E Jolly,
University of Alabama at Birmingham
School of Public Health
1665 University Boulevard, RPHB 217
Birmingham, Alabama 35294-0022
Tel: 205-934-1823
Fax: 205-934-8665
Email: jollyp@uab.edu

losis (TB) co-infection is a major public health problem among people living with HIV, especially in developing countries in Africa. The prevalence of TB is a threat for the general public especially for those with immunosuppressive illnesses other than HIV. The World Health Organization (WHO) estimates that around one-third of people living with HIV in the world are co-infected with TB and that approximately 750,000 people living with HIV develop TB yearly, mostly in sub-Saharan Africa ${ }^{1}$. Kenya has the fourth largest HIV epidemic in the world with an overall prevalence rate of $4.8 \%{ }^{2}$. Although there has been a decline in HIV prevalence 
in Kenya from $10.5 \%$ at its peak in 1996, 1.5 million Kenyans were living with HIV in 2017 and 53,000 were newly infected that year ${ }^{2}$. Forty-two percent of HIV-positive Kenyan adults were on antiretroviral therapy (ART) in $2013^{3}$. Despite the availability and use of ART, opportunistic infections (OIs) continue to cause significant morbidity and mortality among HIV/AIDS patients in low and middle-income countries (LMIC) ${ }^{4}$. This is because approximately 25\% of HIV-infected individuals globally are unaware of their infection status and others who know their status are not on ART, or take ART inconsistently ${ }^{5}$. Further, with the 2013 WHO treatment guidelines that recommend ART initiation in HIV-positive individuals with a CD4 count of $\geq 350$ cells/mm3, and the 2016 "Treat All" guidelines, access to ART is much lower due to a higher number of people who are eligible for treatment $t^{6,7}$.

Among the common HIV OIs in Kenya, TB is the most prevalent (approximately 268 cases per 100,000 populations $)^{8}$. TB is also the single leading cause of death among people living with HIV/AIDS (PLWHA) in Kenya ${ }^{9}$; up to $38 \%$ of people with TB are co-infected with $\mathrm{HIV}^{2}$. One study showed a TB/HIV co-infection rate of $42 \%$ in Western Kenya ${ }^{10}$. A case-control study conducted in Nairobi Province in 2007 found that $61.5 \%$ of $\mathrm{TB}$ cases were co-infected with HIV compared to $38.5 \%$ of non-TB cases $^{11}$. The emergence of drug resistant TB in countries with high HIV prevalence is an additional public health threat to those living with HIV, as well as to the general population. Because of the complex nature of the management of HIV and associated OIs, appropriate implementation of the recommended guidelines for care including prevention and treatment of OIs, use of ART and laboratory and clinical follow-up of patients is of paramount importance. Kenyatta National Hospital (KNH), which is located in the capital city of Nairobi, is the largest referral and teaching hospital in Kenya with an 1,800 bed capacity. KNH serves as the primary hospital for the 4 million residents in Nairobi. $\mathrm{KNH}$ has national guidelines for the management of OIs and use of ART to manage HIV-positive persons ${ }^{12}$. This study was conducted to determine the prevalence and types of HIV/ AIDS-related OIs among patients attending $\mathrm{KNH}$ and to provide information that can be used in interventions for early diagnosis, treatment, and prevention of OIs among HIV patients. This information is essential for review of methods in use for treatment and control of OIs and implementation of clinical strategies and these infections. programs to mitigate the significant burden and cost of

\section{Methods}

Study design, participant recruitment and data collection.

A cross-sectional study was conducted from May to August 2010 among HIV-positive adults $\geq 19$ years old who attended outpatient clinics at KNH. All patients were verified to be on cotrimoxazole or alternate prophylaxis for Pneumocystis jirovecii pneumonia (PCP) and on ART. Selection of the study population was done with the assistance of the clinic staff who reviewed the patient files, identified patients who met the eligibility criteria, informed them of the study and asked if they would be willing to participate. Patients who expressed willingness to participate were then introduced to the research staff by the clinic staff. The research staff informed potential participants about the purpose of the study and asked them to read the informed consent form and to ask questions. After all questions were answered to the satisfaction of the participants, they were asked to sign the informed consent form signifying their willingness to participate in the study. An interviewer-administered questionnaire was then used to collect information on socio-demographic characteristics (age, marital status, level of education, employment, occupation) and years of living with HIV from the participants. Clinical information, such as the most recent $\mathrm{CD} 4+\mathrm{T}$-cell count and diagnosis and treatment of OIs, was extracted from the participants' clinical files that are used by the clinicians during the patients' clinic visits. Diagnosis of OIs was done through clinical diagnosis and verified through laboratory testing where possible. A unique identification number was assigned to each participant's questionnaire (which also contained the clinical data) instead of the patient's name and the highest level of confidentiality of participant information was maintained.

\section{Ethical approval}

This study was reviewed and approved by the Institutional Review Board of the University of Alabama at Birmingham, and University of Nairobi-Kenyatta National Hospital Ethics and Research Committee.

\section{Sample size calculation}

The prevalence of OIs at KNH was previously estimated to be $14 \%{ }^{13}$. Using this prevalence, we estimated that a total sample of 500 persons was required to capture a representative sample of this population with a $95 \%$ confidence and a $5 \%$ margin of error (Statcalc, Epi Info Version 6) 


\section{Statistical analysis}

Statistical analyses of sociodemographic factors, years of living with HIV and CD4 count were conducted on the sample of 500 patients. Categorical variables were reported as counts and percentages, and the Chi-squared or Fisher's exact tests were used to compare categorical variables. Multivariable logistic regression models were fit on the whole dataset to determine factors associated with the three most commonly occurring OIs. The factors included in the models were: age, sex, level of education, employment status, occupation, years living with HIV and CD4 count. Odds ratios (OR), 95\% confidence intervals (CIs), and the p-values for testing the significance of the variables in the model were obtained. All tests with a p-value $\leq 5 \%$ were deemed statistically significant. All analyses were done using the Statistical Analytical System (SAS) software version 9.4 (SAS Institute, Cary, North Carolina).

\section{Results}

Table 1 shows the socio-demographic characteristics and CD4 counts of the 500 participants in the study. Most of the participants $(56.2 \%)$ were $<40$ years old and the highest proportion was in the 33-39 age-group. The majority of participants were married or cohabiting $(54 \%)$, while $15.8 \%$ were divorced or separated, and $14.0 \%$ reported being single (never married). Most participants had received secondary education (46\%), while $29 \%$ had received primary education and $17 \%$ had received tertiary or university education. Overall, $63 \%$ of the patients were unemployed; $71 \%$ reported that they were skilled and $29 \%$ reported being unskilled. A majority of the patients $(72 \%)$ had lived with HIV for $\leq 5$ years while $28 \%$ had lived with HIV for $\geq 6$ years. Most participants had a CD4 count of 200-349 (31\%), while $19.3 \%$ had a CD4 count of $0-199,23.2 \%$ had a CD4 count of $350-499$, and $26.1 \%$ had a CD4 count of $\geq 500$.

Table 1. Socio-demographic characteristics and CD4 counts of participants

\begin{tabular}{|c|c|}
\hline Variable & $\begin{array}{l}\text { Total } \\
(\mathrm{n}=500) \\
\mathrm{n}(\%)\end{array}$ \\
\hline \multicolumn{2}{|l|}{ Age } \\
\hline $19-25$ & $17(3.4)$ \\
\hline $26-32$ & $103(20.6)$ \\
\hline $33-39$ & $161(32.2)$ \\
\hline $40-46$ & $105(21.0)$ \\
\hline $47-53$ & $114(22.8)$ \\
\hline \multicolumn{2}{|l|}{ Marital Status } \\
\hline Married or Cohabiting & $270(54.0)$ \\
\hline Widowed & $79(15.8)$ \\
\hline Divorced/Separated & $79(15.8)$ \\
\hline Single (never married) & $72(14.4)$ \\
\hline \multicolumn{2}{|l|}{ Level of education } \\
\hline None & $14(2.8)$ \\
\hline Primary & $146(29.2)$ \\
\hline Secondary & $230(46.0)$ \\
\hline Vocational/Technical & $25((5.0)$ \\
\hline Tertiary/College/University & $85(17.0)$ \\
\hline \multicolumn{2}{|l|}{ Employed } \\
\hline Yes & $185(37.0)$ \\
\hline No & $315(63.0)$ \\
\hline \multicolumn{2}{|l|}{ Occupation } \\
\hline Skilled & $353(70.6)$ \\
\hline Unskilled & $147(29.4)$ \\
\hline \multicolumn{2}{|l|}{ Years with HIV } \\
\hline $0-5$ & $360(72.0)$ \\
\hline $6-25$ & $140(28.0)$ \\
\hline
\end{tabular}


Table 2 shows the types and percentages of common HIV-related OIs or conditions among the study participants by years of living with HIV. TB, herpes zoster (HZ) and oral thrush (OT) were the three most commonly occurring OIs among participants (see Figure 1). OT (candida infection in the mouth, throat, and esoph- agus) was differentiated from other forms of candidiasis such as vaginal candidiasis and invasive candidiasis.

Of all the conditions studied, only TB was significantly associated with years of HIV infection $(p=0.02)$. Overall, 35\% of the participants had TB. Of those living with HIV for $\leq 5$ years, $31.7 \%$ had TB compared to $43.6 \%$ of participants living with HIV for $\geq 6$ years.

Table 2. Types and prevalence of HIV-related opportunistic infections/conditions by years of HIV infection

\begin{tabular}{|c|c|c|c|c|}
\hline \multirow{2}{*}{ Variable } & \multirow{2}{*}{$\begin{array}{l}\text { Total n (\%) } \\
n=500\end{array}$} & \multicolumn{2}{|c|}{ Years with HIV n (\%) } & \multirow[t]{2}{*}{ P-value } \\
\hline & & $0-5$ & $6-25$ & \\
\hline $\begin{array}{l}\text { Overall } \\
\text { Prevalence of OIs } \\
\end{array}$ & $394(78.8)$ & & & \\
\hline \multicolumn{4}{|l|}{ TB } & \multirow[t]{3}{*}{0.02} \\
\hline Yes & $175(35.0)$ & $114(31.7)$ & $61(43.6)$ & \\
\hline No & $325(65.0)$ & $246(68.3)$ & $79(56.4)$ & \\
\hline \multicolumn{4}{|l|}{ Herpes Zoster } & \multirow[t]{3}{*}{0.1} \\
\hline Yes & $77(15.4)$ & $49(13.6)$ & $28(20.0)$ & \\
\hline No & $423(84.6)$ & $311(86.4)$ & $112(80.0)$ & \\
\hline \multicolumn{4}{|l|}{ Oral Thrush } & \multirow[t]{3}{*}{0.1} \\
\hline Yes & $40(8.0)$ & $24(6.7)$ & $16(11.4)$ & \\
\hline No & $460(92.0)$ & $336(93.3)$ & $124(88.6)$ & \\
\hline \multicolumn{4}{|l|}{ URI } & \multirow[t]{3}{*}{0.13} \\
\hline Yes & $29(5.8)$ & $17(4.7)$ & $12(8.6)$ & \\
\hline No & $471(94.2)$ & $343(95.3)$ & $128(91.4)$ & \\
\hline \multicolumn{4}{|l|}{ Candidiasis } & \multirow[t]{3}{*}{0.18} \\
\hline Yes & $26(5.2)$ & $22(6.1)$ & $4(2.9)$ & \\
\hline No & $474(94.8)$ & $338(93.9)$ & $136(97.1)$ & \\
\hline \multicolumn{4}{|c|}{ Cryptococcal Meningitis } & \multirow[t]{3}{*}{0.64} \\
\hline Yes & $23(4.6)$ & $18(5.0$ & $5(3.6)$ & \\
\hline No & $477(95.4)$ & $342(95.0)$ & $135(96.4)$ & \\
\hline \multicolumn{4}{|l|}{ Diarrhea } & \multirow[t]{3}{*}{0.42} \\
\hline Yes & $17(3.4)$ & $14(3.9)$ & $3(2.1)$ & \\
\hline No & $483(96.6)$ & $346(96.1)$ & $137(97.9)$ & \\
\hline \multicolumn{4}{|l|}{$\begin{array}{l}\text { Kaposi's } \\
\text { Sarcoma }\end{array}$} & \multirow[t]{3}{*}{0.68} \\
\hline Yes & $7(1.4)$ & $6(1.7)$ & $1(0.7)$ & \\
\hline No & $493(98.6)$ & $354(98.3)$ & $139(99.3)$ & \\
\hline
\end{tabular}




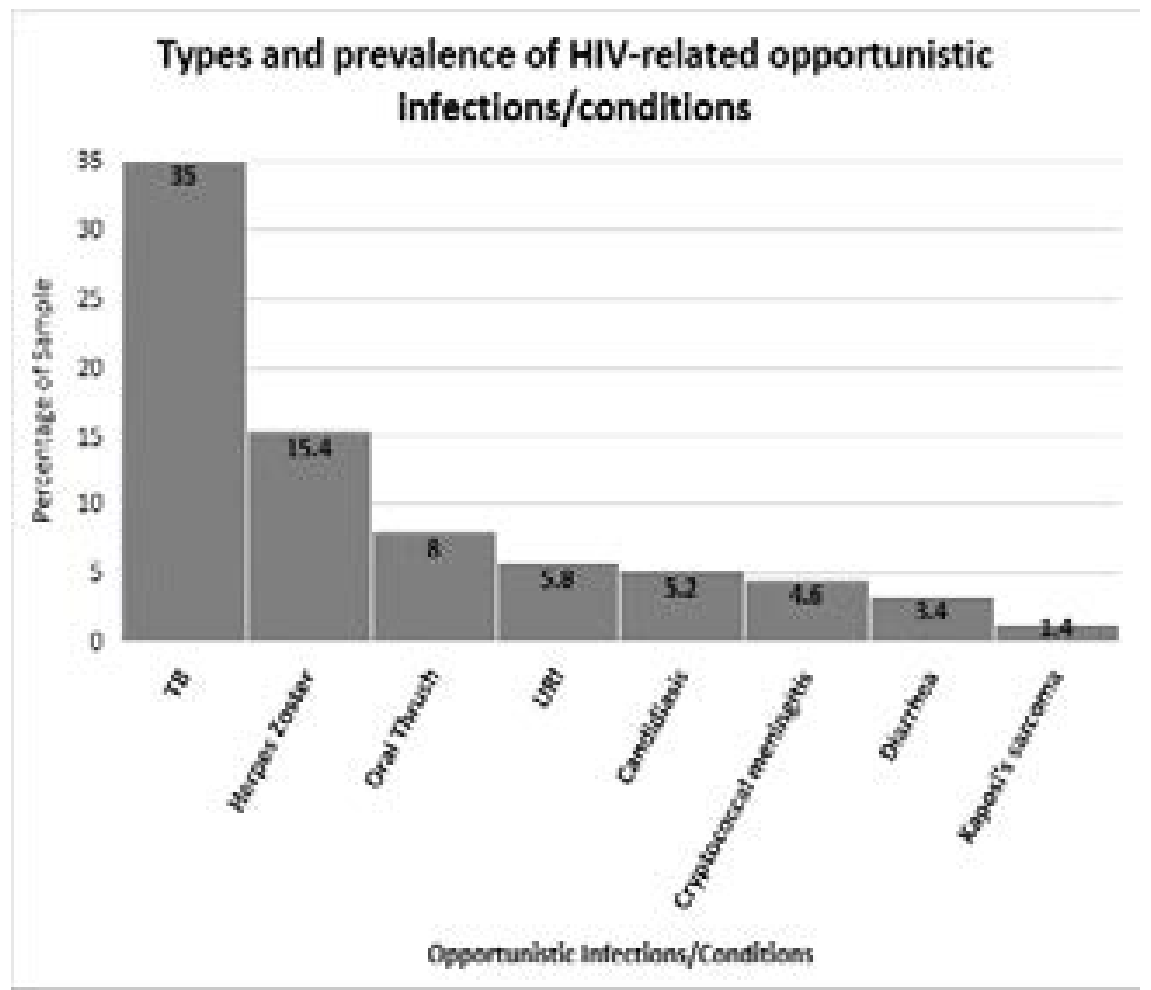

Figure 1: Types and prevalence of HIV-related opportunistic infections/conditions

Table 3 shows the odds ratio and 95\% CIs of sociodemographic factors, years of living with HIV, and CD4 count associated with TB, HZ, and OT. Only years of living with HIV significantly predicted participants having TB $(\mathrm{p}=0.01)$. Patients who lived with HIV for $\leq 5$ years had lower odds of developing TB compare with those who lived with HIV for $\geq 6$ years (AOR = $0.53,95 \% \mathrm{CI}=0.34,0.83)$. Participants with lower CD4 counts of 0-199 and 200-349 had two times greater odds of having TB than those with CD4 count of $\geq$
$500(\mathrm{AOR}=1.94,95 \% \mathrm{CI}=1.04,3.64$ and $\mathrm{AOR}=$ $1.84,95 \% \mathrm{CI}=1.05,3.22$, respectively).

None of the factors predicted HZ. However, it is interesting to note that patients with primary and vocational/technical education had 3 times and almost 5 times greater odds of having $\mathrm{HZ}$ than participants with tertiary or college education $(\mathrm{AOR}=3.05,95 \% \mathrm{CI}=$ $1.01,9.23$ and $\mathrm{AOR}=4.98,95 \% \mathrm{CI}=1.24,20.07$, respectively). Type of occupation was a predictor of OT $(\mathrm{p}=0.04)$; skilled workers had lower odds of having OT than unskilled workers $(\mathrm{AOR}=0.37,95 \% \mathrm{CI}=0.41$, $0.97)$. 


\begin{tabular}{|c|c|c|c|}
\hline \multirow{2}{*}{ Variable } & \multicolumn{3}{|l|}{$\operatorname{AOR}(95 \% \mathrm{CI})$} \\
\hline & \begin{tabular}{|l|} 
Tuberculosis \\
\end{tabular} & Herpes Zoster & Oral Thrush \\
\hline Age (years) & $(\mathrm{P}$-value $=0.15)$ & $(\mathrm{P}$-value $=0.81)$ & $(\mathrm{P}$-value $=0.63)$ \\
\hline $19-25$ & $0.86(0.21,3.57)$ & $1.16(0.21,6.3)$ & $0.73(0.08,6.90)$ \\
\hline $26-32$ & $1.8(0.94,3.43)$ & $0.91(0.42,1.98)$ & $0.40(0.12,1.39)$ \\
\hline $33-39$ & $1.91(1.07,3.42)$ & $0.70(0.34,1.43)$ & $0.91(0.35,2.33)$ \\
\hline $40-46$ & $1.89(1.00,3.55)$ & $1.06(0.51,2.20)$ & $1.06(0.39,2.88)$ \\
\hline $47-53$ & Referent & Referent & Referent \\
\hline Sex & $(\mathrm{P}$-value $=0.2)$ & $(\mathrm{P}$-value $=0.87)$ & $(\mathrm{P}$-value $=0.66)$ \\
\hline Male & $1.35(0.85,2.14)$ & $1.05(0.58,1.90)$ & $0.83(0.37,1.89)$ \\
\hline Female & Referent & Referent & Referent \\
\hline Level of Education & $(\mathrm{P}$-value $=0.79)$ & $(\mathrm{P}$-value $=0.2)$ & $(\mathrm{P}$-value $=0.66)$ \\
\hline None & $1.06(0.23,4.81)$ & $1.93(0.30,12.63)$ & $0.38(0.03,4.12)$ \\
\hline Primary & $1.3(0.63,2.66)$ & $3.05(1.01,9.23)$ & $0.58(0.18,1.91)$ \\
\hline Secondary & $1.47(0.78,2.75)$ & $2.74(0.99,7.63)$ & $0.54(0.19,1.50)$ \\
\hline Vocational/Technical & $1.47(0.49,4.37)$ & $4.98(1.24,20.07)$ & $0.24(0.03,2.22)$ \\
\hline Tertiary/College/University & Referent & Referent & Referent \\
\hline Employed & $(\mathrm{P}$-value $=0.47)$ & $(\mathrm{P}$-value $=0.34)$ & $(\mathrm{P}$-value $=0.21)$ \\
\hline Yes & $0.83(0.50,1.37)$ & $1.38(0.71,2.67)$ & $1.79(0.72,4.46)$ \\
\hline No & Referent & Referent & Referent \\
\hline Occupation & $(\mathrm{P}$-value $=0.2)$ & $(\mathrm{P}$-value $=0.08)$ & $\left(P\right.$-value $\left.=0.04^{*}\right)$ \\
\hline Skilled & $1.43(0.83,2.46)$ & $0.54(0.28,1.07)$ & $0.37(0.41,0.97)$ \\
\hline Unskilled & Referent & Referent & Referent \\
\hline Years with HIV & $\left(\mathrm{P}\right.$-value $\left.=0.01^{*}\right)$ & $(\mathrm{P}$-value $=0.09)$ & $(\mathrm{P}$-value $=0.15)$ \\
\hline $0-5$ & $0.53(0.34,0.83)$ & $0.63(0.36,1.08)$ & $0.58(0.28,1.21)$ \\
\hline $6+$ & Referent & Referent & Referent \\
\hline $\begin{array}{l}\text { CD4 count (cells } / \mathrm{mm} 3 \\
\text { blood) }\end{array}$ & $(\mathrm{P}$-value $=0.12)$ & $(\mathrm{P}$-value $=0.67)$ & $(\mathrm{P}$-value $=0.93)$ \\
\hline $0-199$ & $1.94(1.04,3.64)$ & $1.00(0.44,2.27)$ & $1.41(0.49,4.04)$ \\
\hline 200-349 & $1.84(1.05,3.22)$ & $1.46(0.72,2.95)$ & $1.10(0.42,2.88)$ \\
\hline $350-499$ & $1.42(0.78,2.61)$ & $1.25(0.59,2.65)$ & $1.10(0.40,3.08)$ \\
\hline$\geq 500$ & Referent & Referent & Referent \\
\hline
\end{tabular}

* Significant association with the $\mathrm{OI}, \mathrm{P}<0.05$ statistically significant.

\section{Discussion}

In this study participants presented with common HIV-related OIs or conditions such as TB, herpes zoster (HZ), oral thrush (OT), diarrhea and Kaposi's sarcoma. The World Health Organization (WHO) and the Joint United Nations Programme on HIV/AIDS (UNAIDS) recommended the use of co-trimoxazole prophylaxis for HIV-infected adults in Africa with symptomatic HIV disease (stage II, III or IV of the WHO classification of HIV infection and disease) and for asymptomatic individuals with CD4 T-lymphocyte count of $\leq 500 \times 106 / 1$ or total lymphocyte count (TLC) equivalent in late $2000^{14}$. Thus all of the patients were on cotrimoxazole prophylaxis and none presented with Pneumocystis Jerovencii pneumonia (PCP) indicating that cotrimoxazole prophylaxis implementation was effective. However, this study was conducted in 2010 shortly after the WHO 2010 ART guidelines were implemented. Although KNH began implementing the guidelines, the patients might not have been on ART 
long enough for their immune systems to recover enough to prevent the HIV-related OIs/conditions that were observed. Further, since the study was cross-sectional, we were recruiting patients at different stages of HIV infection and who were on ART for different periods of time.

In this study years of living with HIV was found to be a predictor of TB infection. Participants who were living with HIV for $\leq 5$ years were $47 \%$ less likely to have TB compared to those living with HIV for $\geq 6$ years. This is understandable since HIV weakens the immune system over time and increases the risk for TB infection ${ }^{15}$. An earlier study done in Kenya showed that as the HIV epidemic peaked in the mid-1990s (1994-1996) the annual risk of TB infection was higher than during the earlier years of 1986-1990 ${ }^{16}$. Other studies conducted in Zambia and the US also showed significant associations between $\mathrm{HIV}$ infection and prevalent $\mathrm{TB}^{17,18}$. The study by Ayles et al. showed that $36 \%$ of prevalent TB could be attributed to HIV infection, while the study by DeRiemer et al. found that TB cases were nearly eight times higher among HIV-infected than non-HIV-infected persons ${ }^{17,18}$. A recent case-control study on factors associated with TB infection among people living with HIV / AIDS in China found that $15.7 \%$ of subjects were diagnosed with active TB. Similar to our study, this study showed that long duration of HIV infection was an independent risk factor for TB 19. Our study also showed a significant relationship between CD4 count and TB infection. Patients with CD4 counts of 0-199 or 200-349 had approximately 2 times higher odds of having TB infection. This has also been seen in other studies and is known to occur as a result of loss of CD4 cells and impairment of the immune system in HIV ${ }^{19-21}$.

At the time of our study in 2010, the Kenyan standard ART regimen was in-line with the WHO's recommendation of November 2009 which called for ART initiation when the CD4 count dropped to 350 cells $/ \mu \mathrm{L}$ or below ${ }^{22}$. With timely initiation of appropriate ART, and adherence to ART, less cases of TB and other OIs should be observed. Many studies have shown that the use of ART has substantially reduced morbidity and mortality from OIs among HIV-positive individuals since its introduction ${ }^{19,23}$. However, in Kenya and other developing countries, many HIV cases are diagnosed late in infection when the CD4 count has already dropped low and patients present to clinics with OIs. The ART guidelines were revised in 2013 calling for initiation of ART in all HIV-positive individuals with a
CD4 count of $>350$ cells $/ \mathrm{mm}^{3}$ and $\leq 500$ cells $/ \mathrm{mm}^{3}$ regardless of WHO clinical stage, and initiation of ART in all HIV-positive individuals with active TB disease ${ }^{6}$. The WHO again revised the ART guidelines in 2015 to recommend that ART should be initiated in everyone living with HIV at any CD4 cell count ${ }^{7}$. TB may go undiagnosed in HIV patients with mild clinical signs and atypical imaging as occurs in people with impaired immune systems ${ }^{17}$. Undiagnosed TB is a major challenge to TB control; therefore, vigilant clinical evaluations for HIV patients with atypical TB presentation need to be worked into the management of HIV patients, especially those who have been infected with HIV for a longer duration of time or those with lower CD4 counts.

In this study, $15.4 \%$ of patients had $\mathrm{HZ}$, similar to the rate of $\mathrm{HZ}$ infection in $\mathrm{HIV}$ patients found in another study24. Other studies have shown that HIV-infected patients have a higher incidence of $\mathrm{HZ}$ than the general population even after the institution of $\mathrm{ART}^{25-27}$. We found that patients with lower levels of education (primary and vocational/technical) were 3 and 5 times more likely to have $\mathrm{HZ}$ infection, respectively, than those with tertiary or college education. Although none of the studies that we reviewed looked at educational level of HIV patients with HZ, they showed a higher incidence of $\mathrm{HZ}$ among white patients at an urban Veterans Affairs Medical Center or that HZ infection occurred predominantly among urban African-American patients who may be of lower economic status and educational level ${ }^{24-26}$. Our finding that patients with lower educational levels were more likely to have HZ may indicate that it took a longer time for these patients to be diagnosed with HIV or to receive ART. Before ART, the incidence of $\mathrm{HZ}$ in HIV patients was 10-30 times higher than in HIV-negative individuals ${ }^{28,29}$. Studies have shown that although $\mathrm{HZ}$ seems to increase shortly after initiation of ART due to Immune Reconstitution Inflammatory Syndrome (IRIS), there has been a significant decrease in $\mathrm{HZ}$ incidence since the introduction of ART $^{24,25,30,31}$.

The prevalence of OT in our study was $8 \%$ which is in agreement with the lower level reported from a recent meta-analysis of oral candida among HIV-infected individuals in African populations; prevalence rates ranging from $7.6 \%$ to $75.3 \%$ were reported ${ }^{32}$. The variations in prevalence may be due to differences in diagnostic techniques, geographic and/or ethnic differences, and orahygiene among the participants. We found an association between type of occupation and OT among our 
HIV patients; patients with skilled occupations were 63\% less likely to have OT than those with unskilled occupations. Unskilled workers may have had poorer oral hygienic practices, less health care, and poorer access to early HIV care than skilled workers. There is need to strengthen the capacity for oral hygiene and fungal diagnosis and effective treatment in Kenya and other African populations.

\section{Conclusion}

The findings of this study highlight the need for improvement of the rates of screening, early detection of TB and HIV infections and management of HIV and OIs in Kenya. Coordination and integration of diagnostic services and preventive care for TB and HIV is essential for their control. Active case finding programs should be initiated so that ART can be initiated early among those infected with HIV to decrease the burden of OIs. Patients found with latent TB should be given preventive therapy to avoid active TB disease. Additionally, annual TB screening of HIV-positive individuals, with increased clinical evaluation of those infected with HIV for a longer duration of time (or with a low CD4 count), regardless of clinical symptoms, should help to reduce the occurrence of TB and other OIs. Physicians should look carefully for indicators of TB such as IRIS during treatment of HIV patients especially as TB may present atypically in HIV patients ${ }^{33}$. Enhancement of TB infection control measures to prevent transmission of disease within health care facilities, and appropriate management of both HIV and TB infections should be instituted in order to decrease morbidity and mortality among infected persons. Since TB is both curable and preventable, urgent action is required to prevent, diagnose, and treat the infection in people living with HIV, their families and community members.

\section{Study Limitations}

This study has certain limitations that should be considered in interpreting the results. The main limitation is the cross-sectional study design which does not allow determination of causality. Some OIs and other HIV/ AIDS related conditions may have gone undetected due to subclinical presentation and incomplete screening resulting in potential underestimation of the different conditions. Since our study sample was drawn from patients attending outpatient clinics at $\mathrm{KNH}$, the sample may not be fully representative of the population of Nairobi. However, KNH draws people from all over Nairobi and other areas of Kenya.

\section{Conflict of interest}

The authors declare that have no conflicts of interest.

\section{Authors' contributions}

GC and WJ conceived the study. PJ, NY and GC provided information on experimental methods and design. GC and WJ collected the data. OM performed statistical analysis and interpreted the data. PJ, NY, OM and GC drafted and revised the manuscript. All authors read and approved the final manuscript.

\section{References}

1. World Health Organization. WHO Three I's Meeting: Intensified Case Finding (ICF), Isoniazid Preventive Therapy (IPT) and TB Infection Control (IC) for people living with HIV. Geneva, Switzerland: World Health Organization; 2008 April. 14p.

2. Avert. HIV and AIDS in Kenya Internet. AVERT; 2018 May 21 Updated 2018 Dec 10; Cited 2019 Jan 7. Available from: http://www.avert.org/professionals/ hiv-around-world/sub-saharan-africa/kenya.

3. Joint United Nations Programme on HIV/AIDS. The Gap Report. Geneva, Switzerland: UNAIDS; 2014 July. 422p.

4. Avila D, Althoff KN, Mugglin C, Wools-Kaloustian $\mathrm{K}$, Koller M, Dabis F, et al. Immunodeficiency at the start of combination antiretroviral therapy in low-, middle-, and high-income countries. I Acquir Immune Defic Syndr. 2014; 65(1):e8-16.

5. Joint United Nations Programme on HIV/AIDS. Global HIV \& AIDS statistics - 2018 fact sheet Internet. UNAIDS; 2018 Cited 2018 Dec 6. Available from: http://www.unaids.org/en/resources/fact-sheet.

6. World Health Organization. Consolidated guidelines on the Use of Antiretroviral Drugs for Treating and Preventing HIV Infection: Summary of key features and recommendations. Geneva, Switzerland: World Health Organization Department of HIV/AIDS; 2013 June. 16p.

7. World Health Organization. Consolidated Guidelines on The Use of Antiretroviral Drugs for Treating and Preventing HIV Infection: Recommendations for A Public Health Approach Second Edition. Geneva, Switzerland: World Health Organization Department of HIV/AIDS; 2016. 480p.

8. TBFACTS.ORG. TB Statistics - Incidence, prevalence, high burden Internet. 2018 Cited 2019 Jan 6. Available from: http://tbfacts.org/tb-statistics/.

9. Centers for Disease Control and Prevention. Kenya Exceeds Goals to Address TB and HIV Coinfection In- 
ternet. CDC; 2015 March 24 Cited 2019 Jan 6. Available from: http://www.cdc.gov/globalhealth/countries/ kenya/blog/kenya_tb.htm.

10. Nyamogoba HD, Mbuthia G, Mining S, Kikuvi G, Biegon R, Mpoke S, et al. HIV co-infection with tuberculous and non-tuberculous mycobacteria in western Kenya: challenges in the diagnosis and management. Afr Health Sci. 2012;12(3):305-311.

11. Muture BN, Keraka MN, Kimuu PK, Kabiru EW, Ombeka VO, Oguya F. Factors associated with default from treatment among tuberculosis patients in Nairobi province, Kenya: A case control study. BMC Public Health. 2011;11:696.

12. National AIDS and STI Control Program (NASCOP). Guidelines for Antiretroviral Therapy in Kenya 4th Edition. Nairobi, Kenya: National AIDS and STI Control Programme; 2011. 230p.

13. Awino MS. Prevalence and Management of Opportunistic Infections in HIV-Infected Children dissertation. Nairobi, Kenya: University of Nairobi School of Pharmacy; 2008 Sept. 75p.

14. World Health Organization/UNAIDS (2000) Provisional WHO/UNAIDS Recommendations on the Use of Cotrimoxazole Prophylaxis in Adults and Children Living with HIV/AIDS in Africa: World Health Organization/UNAIDS Geneva, October, 2000. African Health Sciences Vol 1 No 1 August 2001. Available at http://www.bioline.org.br/pdf?hs01011. Accessed $09 / 13 / 2019$

15. Mayer K, Hamilton C. Synergistic pandemics: confronting the global HIV and tuberculosis epidemics. Clin Infect Dis. 2010 May 15;50 Suppl 3:S67-70.

16. Odhiambo JA, Borgdorff MW, Kiambih FM, Kibuga DK, Kwamanga DO, Ng'ang'a L, et al. Tuberculosis and the HIV Epidemic: Increasing Annual Risk of Tuberculosis Infection in Kenya, 1986-1996. Am J Public Health. 1999 July; 89(7): 1078-1082.

17. Ayles H, Schaap A, Nota A, Sismanidis C, Tembwe R, De Haas P, et al. Prevalence of Tuberculosis, HIV and Respiratory Symptoms in Two Zambian Communities: Implications for Tuberculosis Control in the Era of HIV. PLoS One. 2009; 4(5): e5602.

18. DeRiemer K, Kawamura LM, Hopewell PC, Daley CL. Quantitative impact of human immunodeficiency virus infection on tuberculosis dynamics. Am J Respir Crit Care Med. 2007;176(9):936-944.

19. Cui Z, Lin M, Nie S, Lan R. Risk factors associated with Tuberculosis (TB) among people living with HIV/ AIDS: A pair-matched case-control study in Guangxi, China. PLoS One. 2017 Mar 30;12(3):e0173976.

20. Taarnhøj GA, Engsig FN, Ravn P, Johansen IS, Lars- en CS, Røge B, et al. Incidence, risk factors and mortality of tuberculosis in Danish HIV patients 1995-2007. BMC Pulm Med. 2011; 11: 26.

21. Reid MJ, Shah NS. Approaches to tuberculosis screening and diagnosis in people with HIV in resource-limited settings. Lancet Infect. Dis. 2009; 9:173184 PubMed.

22. Hontelez JA, de Vlas SJ, Tanser F, Bakker R, Bärnighausen T, Newell ML, et al. The impact of the new WHO antiretroviral treatment guidelines on HIV epidemic dynamics and cost in South Africa. PLoS One. 2011;6(7):e21919.

23. Egger M, Hirschel B, Francioli P, Palella FJ, Delaney $\mathrm{KM}$, et al. Timing of initiation of antiretroviral therapy in AIDS-free HIV-1-infected patients: a collaborative analysis of 18 HIV cohort studies. Lancet. 2009 Apr 18; 373(9672): 1352-1363.

24. Moanna A, Rimland D. Decreasing incidence of herpes zoster in the highly active antiretroviral therapy era. Clin Infect Dis. 2013 Jul;57(1):122-125.

25. Blank LJ, Polydefkis MJ, Moore RD, Gebo KA. Herpes zoster among persons living with HIV in the current antiretroviral therapy era. J Acquir Immune Defic Syndr. 2012;61(2):203-207.

26. Gebo KA, Kalyani R, Moore RD, Polydefkis MJ. The incidence of, risk factors for, and sequelae of herpes zoster among HIV patients in the highly active antiretroviral therapy era. J Acquir Immune Defic Syndr. 2005 Oct 1;40(2):169-174.

27. Song JY, Lee JS, Jung HW, Choi HJ, Lee JS, Eom JS, et al. Herpes zoster among HIV-infected

patients in the highly active antiretroviral therapy era: Korean HIV cohort study. J Acquir Immune Defic Syndr. 2010 Mar 1; 53(3):417-418.

28. Buchbinder SP, Katz MH, Hessol NA, Liu JY, O'Malley PM, Underwood R, et al. Herpes zoster and human immunodeficiency virus infection. I Infect Dis. 1992; 166:1153-1156.

29. Friedman-Kien AE, Lafleur FL, Gendler E, Hennessey NP, Montagna R, Halbert S, et al. Herpes zoster: a possible early clinical sign for development of acquired immunodeficiency syndrome in high-risk individuals. $J$ Am Acad Dermatol. 1986; 14:1023-1028.

30. Levin MJ, Anderson JP, Seage GR 3rd, Williams PL. Short-term and long-term effects of highly active antiretroviral therapy on the incidence of herpes zoster in HIV-infected children. J Acquir Immune Defic Syndr. 2009 Feb 1;50(2):182-191.

31. Domingo P, Torres OH, Ris J, Vazquez G. Herpes zoster as an immune reconstitution disease after initiation of combination antiretroviral therapy in patients 
with human immunodeficiency virus type-1 infection. 33. Karmakar S, Sharma SK, Vashishtha R, Sharma Am J Med. 2001; 110:605-609.

A, Ranjan S, Gupta D, et al. Clinical characteristics of

32. Mushi MF, Bader O, Taverne-Ghadwal L, Bii C, tuberculosis-associated immune reconstitution inflamGrob U, Mshana, SE. Oral candidiasis among African matory syndrome in north Indian population of HIV/ human immunodeficiency virus-infected individuals: 10 years of systematic review and meta-analysis from AIDS patients receiving HAART. Clin Dev Immunol. sub-Saharan Africa. J Oral Microbiol. 2017; 9(1):1317579. 